\title{
Walter Bauer, Orthodoxie et hérésie aux débuts du christianisme
}

Paris, Éditions du Cerf, coll. « Patrimoines - Christianisme », 2009, 348 p.

\section{Anna Van den Kerchove}

\section{(2) OpenEdition}

\section{Journals}

Édition électronique

URL : http://journals.openedition.org/assr/21503

DOI : $10.4000 /$ assr. 21503

ISSN : $1777-5825$

Éditeur

Éditions de l'EHESS

Édition imprimée

Date de publication : 31 décembre 2009

ISBN : 978-2-7132-2218-4

ISSN : 0335-5985

Référence électronique

Anna Van den Kerchove, "Walter Bauer, Orthodoxie et hérésie aux débuts du christianisme », Archives de sciences sociales des religions [En ligne], 148 | octobre-décembre 2009, document 148-14, mis en ligne le 16 novembre 2012, consulté le 21 septembre 2020. URL : http://journals.openedition.org/assr/ 21503 ; DOI : https://doi.org/10.4000/assr.21503

Ce document a été généré automatiquement le 21 septembre 2020.

(c) Archives de sciences sociales des religions 


\title{
Walter Bauer, Orthodoxie et hérésie aux débuts du christianisme
}

Paris, Éditions du Cerf, coll. « Patrimoines - Christianisme », 2009, 348 p.

\author{
Anna Van den Kerchove
}

\section{RÉFÉRENCE}

Walter BAUER, Orthodoxie et hérésie aux débuts du christianisme, Paris, Éditions du Cerf, coll. « Patrimoines - Christianisme », 2009, 348 p.

148-14

1 Voici enfin la première traduction française de l'ouvrage fondamental de Walter Bauer sur les hérésies, Rechtgläubigkeit und Ketzerei im ältesten Christentum, édité en 1934. Pourquoi a-t-il fallu attendre si longtemps pour avoir une telle traduction alors que la version anglaise est parue en 1971 ? Ce retard est surtout dû à la politique française de traduction pas très développée, contrairement à ce qui se passe dans le monde anglosaxon. Le premier grand mérite de cette traduction est donc d'exister et de permettre enfin à cet ouvrage d'être non seulement plus connu mais surtout plus lu. La traduction est due à Philippe Vuagnat et a été révisée et complétée par Christina et Simon Mimouni ; elle s'appuie sur la seconde édition de 1964 et comporte le supplément, traduit en français, de Georg Strecker qui accompagnait cette seconde édition.

2 L'ensemble est préfacé par Alain Le Boulluec qui rappelle les circonstances de la rédaction de l'ouvrage en 1934, comment il a été reçu, surtout à partir de l'édition de 1964, et les critiques qui lui ont été faites. Il revient également sur les points forts de cette œuvre, approche méthodologique rigoureuse s'appuyant sur des sources nombreuses. Cette préface constitue une sorte de mini-guide pour lire W. Bauer. Elle rappelle notamment les arguments et les datations de certaines œuvres antiques aujourd'hui remises en cause.

3 La thèse principale de l'auteur est que l'hérésie est antérieure à l'orthodoxie et que les premières manifestations $\mathrm{du}$ christianisme correspondent à ce qui est qualifié 
d'hérétique à partir du IIe siècle. Il étudie les différents grands centres du premier christianisme : Édesse, Égypte, Asie Mineure et Rome. Seule Rome a une communauté chrétienne dont les caractéristiques correspondent à ce qui devient orthodoxie un peu plus tard. W. Bauer en fait donc le fer de lance du triomphe du christianisme. L'intérêt de cet ouvrage, au-delà des erreurs, des arguments à revoir, est d'avoir montré que le christianisme n'est pas monolithique et d'avoir rompu avec le discours, très largement répandu jusqu'au milieu $d u x^{e}$ siècle, d'une orthodoxie première et des hérésies comme des déviations, le tout en s'appuyant sur une large documentation abordée de manière historique.

Depuis 1934, et surtout 1964, la recherche a bien avancée, notamment avec Alain Le Boulluec (La notion d'hérésie dans la littérature grecque, iie-iiie siècles, I-II, Paris, Études augustiniennes, 1985, et "Orthodoxie et hérésie aux premiers siècles dans l'historiographie récente ", dans S. Elm, E. Rebillard, A. Romano (éds.), Orthodoxie, christianisme, histoire, Rome, 2000, pp.303-319) qui proposa l'expression «représentations hérésiologiques » pour sortir des jugements de valeur impliqués par le terme " hérésie » et, plus récemment, avec Daniel Boyarin (Border Lines: The Partition of Judaeo-Christianity, Philadelphie, 2004) et ce que S.C. Mimouni appelle le «New Paradigm» (voir son article «Les origines du christianisme : nouveaux paradigmes ou paradigmes paradoxaux ? Bibliographie sélectionnée et raisonnée » Revue biblique, 115, 2008, pp. 360-382). Les frontières entre les catégories " hérésie » et « orthodoxie » sont peu à peu déplacées, et de nouveaux champs sont explorés: les chercheurs ne s'intéressent plus seulement aux aspects idéologiques et doctrinaux de ces catégories, mais également à leurs aspects sociaux et politiques. La question de l'identité de soi et de l'autre, de sa construction et de sa représentation, est désormais liée à celle de l'«hérésie ». L'intérêt de cette traduction française est de paraître finalement à point nommé, au moment où se déroule ce renouvellement qui atteint peu à peu, à partir du monde anglo-saxon, la scène de la recherche française. Dans ce contexte, il peut être intéressant de revenir aux fondamentaux et de relire les pionniers dans une langue plus accessible par tous en France. 